\title{
Nursing in a Globalized World: Nursing Students with International Study Experience Report Higher Competence at Graduation
}

\author{
Jan Nilsson ${ }^{1,2 *}$, Marianne Carlsson ${ }^{3,4}$, Eva Johansson ${ }^{5}$, Ann-Charlotte Egmar ${ }^{6,7}$, Jan Florin ${ }^{8}$, \\ Janeth Leksell8, Christina Lindholm ${ }^{9}$, Gun Nordström ${ }^{1,10}$, Kersti Theander ${ }^{1,11}$, \\ Bodil Wilde-Larsson"10, Margret Lepp ${ }^{12,13}$, Ann Gardulf ${ }^{2,14}$
}

${ }^{1}$ Department of Health Sciences, Faculty of Health, Science, and Technology, Karlstad University, Karlstad, Sweden

${ }^{2}$ The Japanese Red Cross Institute for Humanitarian Studies, Tokyo, Japan

${ }^{3}$ Department of Public Health and Caring Sciences, Uppsala University, Uppsala, Sweden

${ }^{4}$ Gävle University, Gävle, Sweden

${ }^{5}$ Department of Neurobiology, Care Sciences and Society, Division of Nursing, Karolinska Institutet, Huddinge, Sweden

${ }^{6}$ The Red Cross University College, Stockholm, Sweden

${ }^{7}$ Department of Learning, Informatics, Management and Ethics, Medical Management Centre, Karolinska Institutet, Stockholm, Sweden

${ }^{8}$ School of Health and Social Studies, Dalarna University, Falun, Sweden

${ }^{9}$ Sophiahemmet University, Stockholm, Sweden

${ }^{10}$ Department of Nursing, Hedmark University College, Hedmark, Norway

${ }^{11}$ Primary Care Research Unit, County Council of Värmland, Sweden

${ }^{12}$ Institute of Health and Care Science, University of Gothenburg, Gothenburg, Sweden

${ }^{13} \varnothing$ stfold University College, Halden, Norway

${ }^{14}$ Unit for Clinical Nursing Research, Immunotherapy and Immunology, Division of Clinical Immunology, Department of Laboratory Medicine, Karolinska Institutet at Karolinska University Hospital, Stockholm, Sweden Email: nilj@kau.se

Received 29 September 2014; revised 22 October 2014; accepted 6 November 2014

Academic Editor: Yau Sui Yu, Open University of Hong Kong, China

Copyright (C) 2014 by authors and Scientific Research Publishing Inc.

This work is licensed under the Creative Commons Attribution International License (CC BY). http://creativecommons.org/licenses/by/4.0/

(c) (i) Open Access

\section{Abstract}

Due to globalization, there is a need for nurses with skills and competence in providing safe, com-

\section{${ }^{*}$ Corresponding author.}

How to cite this paper: Nilsson, J., Carlsson, M., Johansson, E., Egmar, A.-C., Florin, J., Leksell, J., Lindholm, C., Nordström, G., Theander, K., Wilde-Larsson, B., Lepp, M. and Gardulf, A. (2014) Nursing in a Globalized World: Nursing Students with International Study Experience Report Higher Competence at Graduation. Open Journal of Nursing, 4, 848-858.

http://dx.doi.org/10.4236/ojn.2014.412090 
petent and culturally appropriate care. The aim of the study was to investigate whether International Study Experiences (ISE) in other countries during basic nursing education had an impact on newly graduated nurses as regards to self-reported competence. Moreover, a second aim was to explore what background factors that facilitated or constituted a hindrance for nursing students to choose to conduct part of their basic nursing education abroad. At 11 Universities/University Colleges (henceforth called Higher Education Institutions [HEIs]) in Sweden, 565 nursing students responded to the Nurse Professional Competence (NPC) Scale. Students with ISE rated their competence significantly higher on three NPC competence areas-"Legislation in nursing and safety planning", "Leadership and development of nursing" and "Education and supervision of staff/students". Background factors that significantly seemed to enhance ISE were living alone, not having children or other commitments in relation to family, international focus at the HEI and previous international experience. Lack of financial means was reported to prevent students from choosing ISE. The study implies that several background factors are of importance whether students choose ISE or not. ISE during basic nursing education might result in better self-reported competence in leading and developing nursing care, including education of future nurses, and in providing safe care.

\title{
Keywords
}

\author{
Internationalization, International Study Experience, Nursing Education, Self-Reported \\ Competence
}

\section{Introduction}

The International Council of Nurses [1] states that nurses deliver $90 \%$ of all healthcare services worldwide. The growing cultural diversity within societies around the world has created a demand for educating culturally competent healthcare professionals [2] [3]. Previous studies have suggested that nursing education should be altered to include and support more global awareness of cultures, ethnic diversity and world views [4]-[8]. Internationalization of nursing is expected to lead to greater cross-cultural understanding and improved practices in workplaces around the world [9].

International educational exchange programs between different countries during basic nursing education have been ongoing for more than 40 years [10]. Studies have been performed to evaluate the effects of these programs on nursing students and have showed that International Study Experiences (ISE) in other countries leads to a sense of more independent behavior and a sense of better confidence and self-reliance. Moreover, an ability to adapt to cultural behaviors, a change in attitudes to others from different backgrounds and cultures and that nursing students experience personal and professional development have been reported [11]-[16]. In a literature review (2002-2009) it is stated that exchange programs serve to develop cultural competence [17], i.e. an increased ability as a nursing student or as a nurse to care for patients from different cultures and work in different countries. However, Kulbok, Mitchell, Glick and Greiner [18] found in their assessment of studies about international nursing student exchange programs that out of the 23 previously conducted studies, only two could be formally labeled as evaluations of these programs. The reason was that the majority of the findings were based on students' feedback rather than based on a more structured program evaluation.

The Swedish Act on Higher Education [19] states that Universities/University Colleges (henceforth called Higher Educational Institutions, HEIs) should actively promote the understanding of other countries and of international conditions. Therefore, several HEIs offer nursing students the possibility to perform one or more of their clinical placements and/or theoretical courses, during their three-year-long nursing education, outside Sweden. To promote internationalization, all HEIs can apply for financial support from the government for internationalization, including scholarships for international students and teacher exchange programs. Linnaeus-Palme is a bilateral exchange program focusing on low-income countries; Nordplus Higher Education program is a mobility and network program within the Nordic and Baltic countries; Minor Field Studies (MFS) is a unilateral program enabling students to collect data in low-income countries for their bachelor or Master thesis and Erasmus is a bilateral exchange program within European Union (EU). Prior to sending students or teachers, the Swedish 
HEI will sign agreements with specific HEIs in other countries to ensure quality.

One example of how ISE can be structured is presented in Table 1. During clinical placement and/or theoretical courses outside Sweden, nursing students participate in care activities under supervision of local nurses and clinical tutors. If choosing a theoretical course abroad the student will attend a local course. Participating in ISE is being credited upon students return to their home University/University Colleges.

The main aim of the study was to investigate whether International Study Experiences in other countries during basic nursing education had an impact on newly graduated nurses as regards to self-reported competence. Moreover, a second aim was to explore what background factors that facilitated or constituted a hindrance for students to choose to conduct part of their basic nursing education abroad.

\section{Methods}

\subsection{The Nurse Professional Competence (NPC) Scale}

The Nurse Professional Competence (NPC) Scale [20] is based on formal national competence requirement set for registered nurses by the Swedish National Board for Health and Welfare [21]. The NPC Scale comprises 88 items regarding self-reported competences considered important for society, the healthcare sector and the nursing profession, to provide safe and high-quality care.

The items comprise eight sub-scales of competence areas. The eight sub-scales have shown to constitute the two overarching themes "Patient-related nursing" (Theme 1) and "Nursing careorganization and development" (Theme 2) as follows:

Theme 1: Patient-related nursing:

- Nursing care;

- Value-based nursing care;

- Medical technical care;

- Teaching/learning and support;

- Documentation and information technology.

Theme 1: Patient-related nursing and Theme 2: Nursing careorganization and development:

- Legislation in nursing and safety planning.

Theme 2: Nursing care organization and development:

- Leadership in and development of nursing;

- Education and supervision of staff/students.

The scale has been evaluated for psychometric properties and has shown satisfactory data quality, reliability and validity. Cronbach's $\alpha$ for the eight factors in the current sample ranged from 0.75 to 0.90 , which indicates high reliability of the scale.

The items in the NPC Scale are formulated as questions, e.g. "Do you think you have the ability to meet patients' basic physical care needs?" The responses are given on a four-point ordinal scale: To a very low degree $=$ 1; To a relatively low degree $=2$; To a relatively high degree $=3$; To a very high degree $=4$. The response alternative "Cannot take a standpoint" is also provided.

Table 1. Example of how ISE including clinical placements and/or theoretical courses can be structured for individual nursing students at different stages in their education.

\begin{tabular}{|c|c|c|c|}
\hline Semester & Course/Program & Country & Length \\
\hline 4 & Emergency Care/unilateral exchange $^{1}$ & India & 5 weeks \\
\hline 5 & Culture and Health/bilateral exchange ${ }^{2}$ & Japan & 4 weeks \\
\hline 5 & Culture and Health/unilateral exchange & Any country & 4 weeks \\
\hline 5 & $\begin{array}{l}\text { Primary health-care and BSc thesis/bilateral exchange funded by the } \\
\text { Linnaeus-Palme program }\end{array}$ & Ghana, Tanzania and Thailand & 12 weeks \\
\hline 5 & $\begin{array}{l}\text { Data collection and analysis for BSc thesis/unilateral exchange funded } \\
\text { by the Minor Field Study program }\end{array}$ & Low-income countries & 8 weeks \\
\hline 6 & $\begin{array}{l}\text { Clinical practice/bilateral exchange within the EU funded Erasmus } \\
\text { program }\end{array}$ & Eleven European countries & 13 weeks \\
\hline
\end{tabular}

${ }^{1}$ With unilateral exchange is meant a one-way program sending students abroad but the HEI not receiving any student from the receiving HEI abroad; ${ }^{2}$ With bilateral exchange is meant a two-way program sending students abroad and also receiving students from the receiving HEI abroad. 
Together with the NPC Scale, questions were also asked regarding background information such as demographic data, previous university studies determined by achieved credits according to the European Credit Transfer System (ECTS), and previous and current work experience in healthcare. One question was posed about ISE, i.e. whether or not the students had participated in ISE during their basic nursing education. Students who answered "yes" to this question also answered questions on the following: number of weeks of education in Europe, number of weeks of education outside Europe, countries chosen for ISE, during which semester (1 to 6) the ISE took place, whether they received the government and/or EU scholarships for ISE such as LinnaeusPalme, Nordplus, Minor Field Studies and/or Erasmus. The newly graduated students answered also a question whether they experienced that the ISE had contributed to perceived competence development. The answers were given by the respondents on a four-point ordinal scale with To a very low degree $=1$, To a low degree $=2$, To a high degree $=3$ and To a very high degree $=4$.

\subsection{Setting, Samples and Data Collection}

The study was performed at 11 HEIs, purposively selected and located in cities throughout Sweden, which offer a nursing program. The 11 HEIs are named A, B C, D, etc. in this paper.

At each HEI, all students completing their final semester of the 3-year nursing program were asked to participate in the study by answering the NPC Scale questionnaire. Data for the study were collected during the students' last week of their education directly prior to graduation. The students responded to the questionnaire anonymously, i.e. without providing any personal information, which would make it possible to trace the questionnaires back to any specific respondent. In total, 565 students participated in the study yielding a response rate of $66 \%$.

One of the HEIs (F) carried out a further data collection using the NPC Scale with in-depth, additional background questions to explore factors influencing and/or preventing students to choose to conduct part of their education abroad. The rationale for choosing HEI $\mathrm{F}$ for the additional data collection was the knowledge of their high number of students who had conducted international studies. This sub-study included 59 students (response rate $72 \%)$; women $\mathrm{n}=49(83 \%)$, mean age $27.8(\mathrm{SD}=6.28)$, upper secondary school (natural science $27 \%$, nursing $9 \%$, social science $42 \%$, other programs $22 \%$ ), experience of university studies prior (32\%) and/or experience from working in health care (58\%) before entering the basic nursing education.

\subsection{Geographical Placement and Length of ISE}

A variety of countries were chosen by the students for their ISE (Figure 1); most students chose Africa ( $\mathrm{n}=21$, $38 \%)$ followed by countries in Europe $(n=18,33 \%)$, Asia $(n=17,31 \%)$ and North- and South America $(n=3$, 3.5\%). For ISE within Europe the median period that students studied abroad was 6 (range 2 - 27) weeks, compared to ISE outside Europe where students had a median study period of 4 (range $2-12$ ) weeks. The majority of the students participated in ISE during the fifth semester of their basic nursing education.

\subsection{Statistical Analyses}

Statistical analyses were conducted using SPSS for Windows, version 19 (SPSS Inc., Chicago, IL, USA). For each of the eight NPC competence areas, a summa score was calculated and then divided with the number of items. Likewise, for each of the two themes a summa score was calculated based on the included sub-scales and then divided by the number of competence areas. Thereafter the summarized scores for the competence areas and the themes were transformed into 1 to 100 scales, the higher the score, the better the perceived competence. Level of statistical significance (p) was set to 0.05 . Descriptive analysis was performed using chi-square statistics. Independent t-test and one-way ANOVA were used to compare mean values between groups. Linear regression analysis was used for comparing sub-scales and themes between groups while controlling for age. Cronbach's alpha was used to measure internal consistency on sub-scales and themes.

\subsection{Ethical Considerations}

According to the current Swedish law of research ethics [22], approval from the Swedish Ethics Committee is not requested for studies based on student questionnaires where identifiable student information is not collected. 


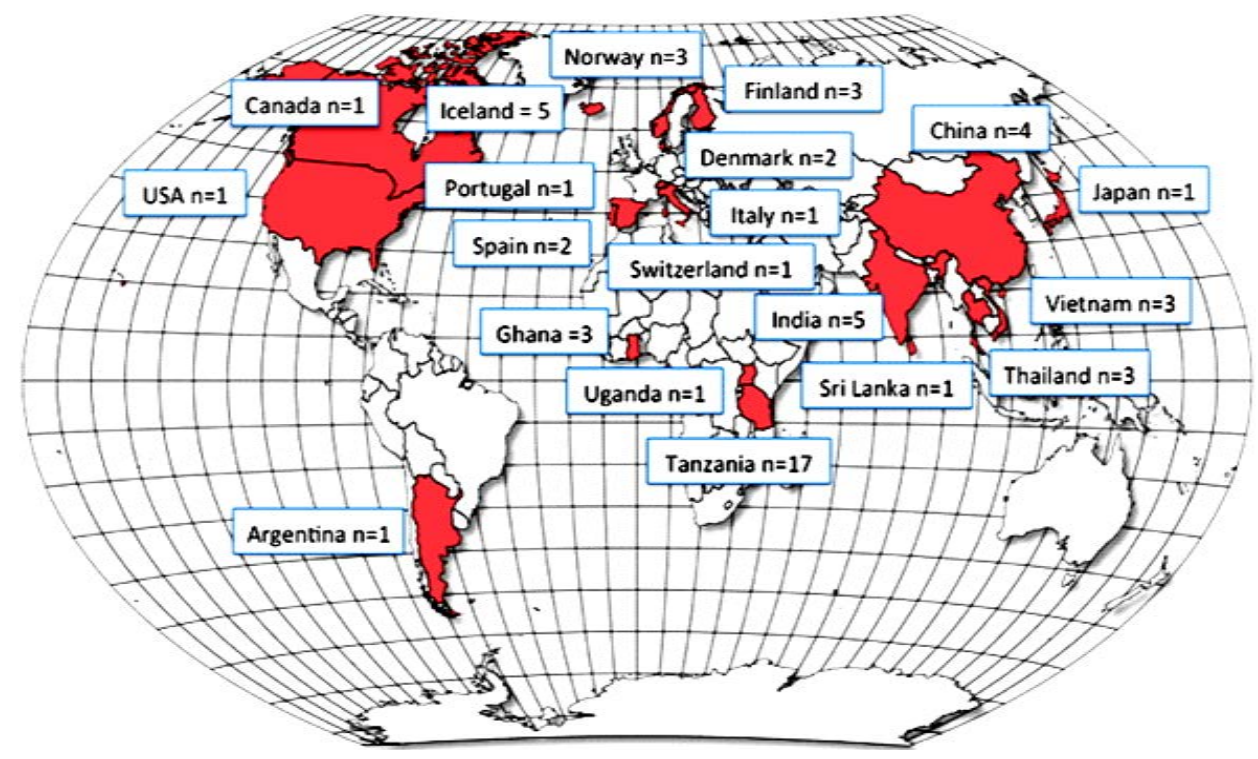

Figure 1. Distribution of countries chosen by the nursing students for part of their education abroad.

The principals of each HEI gave their permission to conduct the study, and oral and written information about participating in the study were given to the nursing students, emphasizing the voluntary notion of participation. Informed consent was obtained from all newly graduated students prior to filling in the questionnaire. The students gave their informed consent by leaving a completed questionnaire which was done anonymously.

\section{Results}

\subsection{Self-Reported Competence among Students with ISE Compared with Students without ISE}

A number of 565 students (mean age 27.6 years, $\mathrm{SD}=6.28$ years) participated in the study; 488 were women $(86.5 \%)$ and 76 men $(13.5 \%)(p=0.383)$ (Table 2$)$. The students with ISE were significantly younger than those not choosing to perform part of their clinical placement and/or theoretical education abroad (25.3 vs. 27.9, $\mathrm{p}<$ 0.001). The group with no ISE had had more experience in health care work before entering the nursing program; however, this was only significant for working as an auxiliary nurse. The most common upper secondary school education for the 565 respondents was the social science program (29\%), followed by the natural science program $(23 \%)$ and auxiliary nursing program $(16 \%)$. About one third $(35 \%)$ of all students had experience of university studies before entering the nursing program (Table 2 ).

In total, $56(10 \%)$ nursing students had chosen to participate in ISE during their basic nursing education (Table 2). However, the proportion of nursing students that had been doing part of their clinical and/or theoretical education abroad differed substantially between the different HEIs (range $0 \%$ to $27 \%$ ) (Figure 2).

Regarding the funding of the ISE programs, the study showed that only six HEIs had students who had utilized any government scholarships. In total, 22/565 students (39\%) were beneficiaries of government scholarships that enabled them to study abroad; the most frequently used was Nordplus Higher Education program ( 8 students at 4 HEIs), followed by Minor Field Study program (6 students at 3 HEIs), Erasmus (5 students at 2 HEIs) and Linnaeus-Palme bilateral exchange program (3 students at 3 HEIs).

As shown in Table 3, nursing students with ISE during their basic nursing education rated their self-reported competence higher, i.e. better, on all competence areas. On three of the eight competence areas the students with ISE rated their competence significantly higher:

- Legislation in nursing and safety planning $(\mathrm{p}<0.05)$ : items about legislation, patients' rights, safety routines, management of violent and/or threatening situations, and knowledge of how to apply principles of disaster medicine;

- Leadership in and development of nursing $(\mathrm{p}<0.01)$ : items about systematic improvements in quality and safety issues, care environment, work environments, utilization and implementation of new knowledge for 
Table 2. Demographic and socioeconomic characteristics for students with or without International Study Experience (ISE). The p-values stand for comparison between students with or without ISE (level of statistical significance was set to 0.05).

\begin{tabular}{|c|c|c|c|c|}
\hline Characteristics & $\begin{array}{c}\text { With ISE } \\
\mathbf{n}=\mathbf{5 6}\end{array}$ & $\begin{array}{l}\text { Without ISE } \\
\mathrm{n}=\mathbf{5 0 9}\end{array}$ & $\begin{array}{c}\text { Total } \\
\mathbf{n}=\mathbf{5 6 5}\end{array}$ & p-values \\
\hline Age, mean (SD) & $25.3(4.33)$ & $27.9(6.45)$ & $27.6(6.28)$ & 0.000 \\
\hline Women \% (n) & $82.1(46)$ & $87.0(442)$ & 86.5 & 0.206 \\
\hline Men \% (n) & $17.9(10)$ & $13.0(66)$ & 13.5 & \\
\hline \multicolumn{5}{|l|}{ Previous upper secondary school education \% (n) } \\
\hline 3-year natural science programme & $30.2(16)$ & $22.3(112)$ & 23.1 & 0.429 \\
\hline 3-year social science programme & $32.1(17)$ & $28.9(145)$ & 29.2 & \\
\hline 3-year auxiliary nursing programme & $11.3(6)$ & $16.3(82)$ & 16.1 & \\
\hline Other programmes & $26.4(14)$ & $32.5(163)$ & 31.9 & \\
\hline University studies prior to entering the basic nursing education $\%$ (n) & $41.1(23)$ & $34.2(174)$ & 34.9 & 0.189 \\
\hline $\begin{array}{l}\text { Work experience in healthcare prior to the basic nursing education } \% \\
\text { (n) }\end{array}$ & $58.9(33)$ & $58.0(294)$ & 58.1 & 0.505 \\
\hline - as auxiliary nurse \% (n) & $72.7(24)$ & $56.1(165)$ & 57.8 & 0.048 \\
\hline - as assistant nurse \% (n) & $27.3(9)$ & $36.1(106)$ & 35.2 & 0.211 \\
\hline - as personal assistant \% (n) & $18.2(6)$ & $20.4(60)$ & 20.2 & 0.486 \\
\hline - other healthcare work (unspecified) \% (n) & $6.1(2)$ & $12.9(38)$ & 12.2 & 0.199 \\
\hline Healthcare work experience in months, mean (SD) & $28.2(64.2)$ & $45.8(93.2)$ & $44.6(91.2)$ & 0.300 \\
\hline $\begin{array}{l}\text { Proportion of students who were working at the same time as } \\
\text { studying during their basic nursing education } \%(\mathrm{n})\end{array}$ & $73.2(41)$ & $69.2(352)$ & 69.6 & 0.323 \\
\hline
\end{tabular}

Table 3. Comparison of self-reported competence for nursing students $(n=565)$ with or without international study experience (ISE) using the Nurse Professional Competence (NPC) Scale (level of statistical significance was set to 0.05).

\begin{tabular}{lccc}
\hline \multicolumn{1}{c}{ Nursing Competences } & $\begin{array}{c}\text { With ISE }{ }^{1}(\mathbf{n}=\mathbf{5 6}), \\
\text { mean (SD) }\end{array}$ & $\begin{array}{c}\text { Without ISE }^{1} \text { (n= 509), } \\
\text { mean (SD) }\end{array}$ & p-values $^{2}$ \\
\hline NPC competence areas & $83.07(9.12)$ & $81.19(9.08)$ & 0.169 \\
Nursing care & $92.06(7.09)$ & $90.24(7.96)$ & 0.088 \\
Value-based nursing care & $77.92(7.56)$ & $75.65(8.44)$ & 0.087 \\
Medical technical care & $80.60(8.98)$ & $78.51(8.70)$ & 0.075 \\
Teaching/learning and support & $88.42(9.97)$ & $86.11(11.36)$ & 0.261 \\
Documentation and information technology & $78.48(8.97)$ & $75.73(9.69)$ & $\mathbf{0 . 0 2 7}$ \\
Legislation in nursing \& safety planning & $80.99(7.43)$ & $77.19(8.06)$ & $\mathbf{0 . 0 0 1}$ \\
Leadership and development of nursing & $76.11(11.38)$ & $69.71(12.32)$ & $\mathbf{0 . 0 0 0}$ \\
Education and supervision of staff/students & & $81.78(5.96)$ & $75.07(6.92)$ \\
\hline NPC themes & $83.34(5.99)$ & $79.04(6.92)$ & 0.054 \\
Patient-related nursing & & $\mathbf{0 . 0 0 0}$ \\
Nursing care organisation and development & & & \\
\hline
\end{tabular}

${ }^{1}$ The results of the NPC scale are presented with values ranging from 1 to 100 , where a score of 100 indicates a very high self-reported competence; ${ }^{2} \mathrm{~T}$-test significance values by regression controlled for age. 


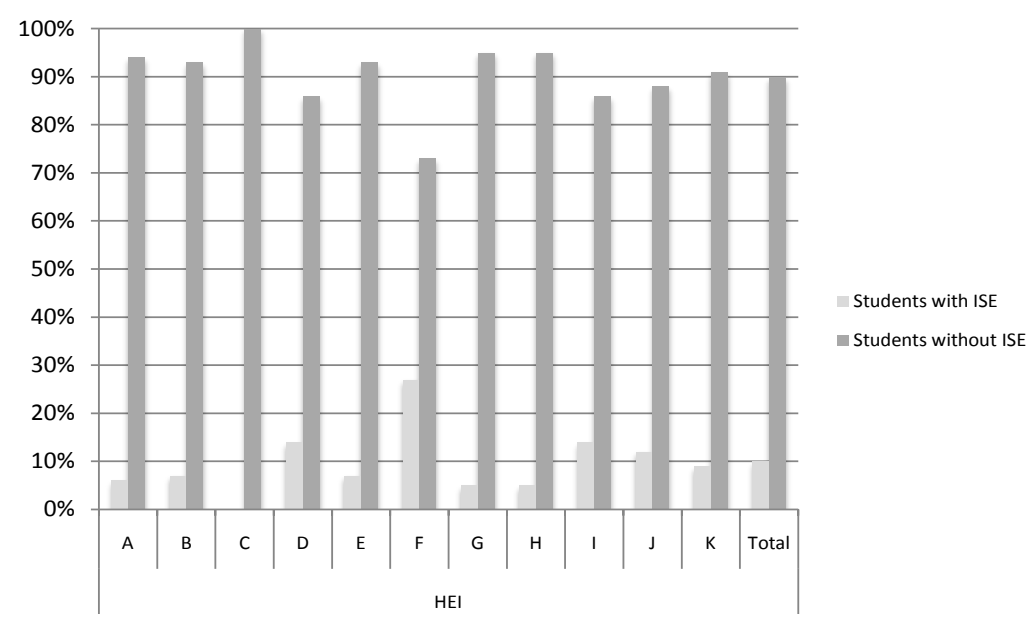

Figure 2. The proportion of nursing students at each HEI that had chosen to participate in International Study Experience (ISE) programs. The proportion ranged from $0 \%$ to $27 \%$.

evidence-based nursing, initiation and participation in research, how to lead, develop and evaluate health staff teams, handle groups and manage conflicts, provide patient-focused care with an emphasis on quality and cost-effectiveness, lead and provide nursing care based on best knowledge, and participate in strategic planning and evaluation;

- Education and supervision of staff/students $(\mathrm{p}<0.001)$ : items about teaching, supervision and evaluation of staff/students.

A significantly higher score was also seen for the theme "Nursing care organization and development" $(\mathrm{p}<$ 0.001) (Table 3).

On average, $80 \%$ of the nursing students with ISE reported that the clinical placement and/or theoretical education to a high/very high degree had contributed to improve their competence (Figure 3). Looking at the individual HEIs, at 8 out of 11 HEIs, the majority of the nursing students reported that ISE had contributed to their competence development.

\subsection{Factors Impacting on Students Participation in ISE}

Among the 59 students participating in the sub-study data collection to explore factors that facilitated or constituted a hindrance for students to choose to conduct part of their education abroad, 20 had participated in ISE (Table 4).

As shown in Table 4, background factors that significantly enhanced ISE were living alone, not having children or other commitments in relation to family, international focus at the HEI and previous international work/ study experience. A factor that prevented nursing students from choosing ISE was a lack of financial means.

\section{Discussion}

The study showed that directly prior to their graduation, nursing students with International Study Experience (ISE) rated their own competence in nursing as significantly higher with regard to the following three competence areas: "legislation in nursing and safety planning", "leadership and development of nursing" and "education and supervision". Furthermore, the majority of the students who carried out part of their education abroad considered that this experience had contributed positively to their competence development. It was also found that few students had received government grants for ISE, although lack of financial means was reported to prevent nursing students from conducting ISE.

A recent review of 26 studies has identified the following six areas where newly graduated nurse students lacked competence: communication, leadership, organization, critical thinking, specific situations, and stress management [23]. The current study indicates that ISE during nursing education could bridge part of these gaps. In the current, unique study where self-reported competence was measured, it was found that ISE did in fact lead to a better ability in leading and developing nursing care, including education of future nurses, and in providing 
Table 4. Demographic and organisational background factors influencing nursing students $(\mathrm{n}=59)$ at one of the HEIs to conduct international study experience (ISE) or not. Data are given as percentages (\%) of students (level of statistical significance was set to 0.05 ).

\begin{tabular}{|c|c|c|c|}
\hline Factors & With ISE $(n=20)$ & Without ISE $(n=39)$ & p-values \\
\hline \multicolumn{4}{|l|}{$\operatorname{Age}^{1}$} \\
\hline $22-26$ years & 65.0 & 46.2 & 0.136 \\
\hline $27-44$ years & 35.0 & 53.8 & \\
\hline \multicolumn{4}{|l|}{ Sex } \\
\hline Women & 95.0 & 76.9 & 0.078 \\
\hline Men & 5.0 & 23.1 & \\
\hline \multicolumn{4}{|l|}{ Living situation } \\
\hline Living alone & 40.0 & 20.5 & \\
\hline Living in a relation & 45.0 & 76.9 & 0.032 \\
\hline Living with other adults & 15.0 & 2.6 & \\
\hline \multicolumn{4}{|l|}{ Having children } \\
\hline Yes & 0 & 35.9 & 0.001 \\
\hline No & 100.0 & 64.1 & \\
\hline \multicolumn{4}{|l|}{ Commitments beside the nursing studies ${ }^{2}$} \\
\hline Yes & 10.0 & 46.2 & 0.005 \\
\hline No & 90.0 & 53.8 & \\
\hline \multicolumn{4}{|l|}{ Ill health } \\
\hline Yes & 0 & 0 & \\
\hline No & 100.0 & 100.0 & \\
\hline \multicolumn{4}{|l|}{ Lack of finances } \\
\hline Yes & 0 & 48.7 & \\
\hline No & 100.0 & 51.3 & 0.000 \\
\hline \multicolumn{4}{|c|}{ Perceiving that the HEI had an international focus } \\
\hline Yes & 55.0 & 20.5 & 0.009 \\
\hline No & 45.0 & 79.5 & \\
\hline \multicolumn{4}{|l|}{ Previous studies/work abroad } \\
\hline Yes & 65.0 & 35.9 & 0.032 \\
\hline No & 35.0 & 64.1 & \\
\hline \multicolumn{4}{|c|}{$\begin{array}{l}\text { Perception that the ISE can negatively affect the ability to } \\
\text { learn necessary skills for the Swedish health care }\end{array}$} \\
\hline Yes & 10.0 & 23.1 & 0.195 \\
\hline No & 90.0 & 76.9 & \\
\hline \multicolumn{4}{|l|}{ Other reasons $^{3}$} \\
\hline Yes & 20.0 & 53.0 & 0.012 \\
\hline No & 80.0 & 46.2 & \\
\hline
\end{tabular}

${ }^{1}$ Categorization of age is based on median value; ${ }^{2}$ Responsibility for other family members, such as parents and/or siblings; ${ }^{3}$ E.g. responsible for own pet/s, not wanting to be away from home for such a long period. 


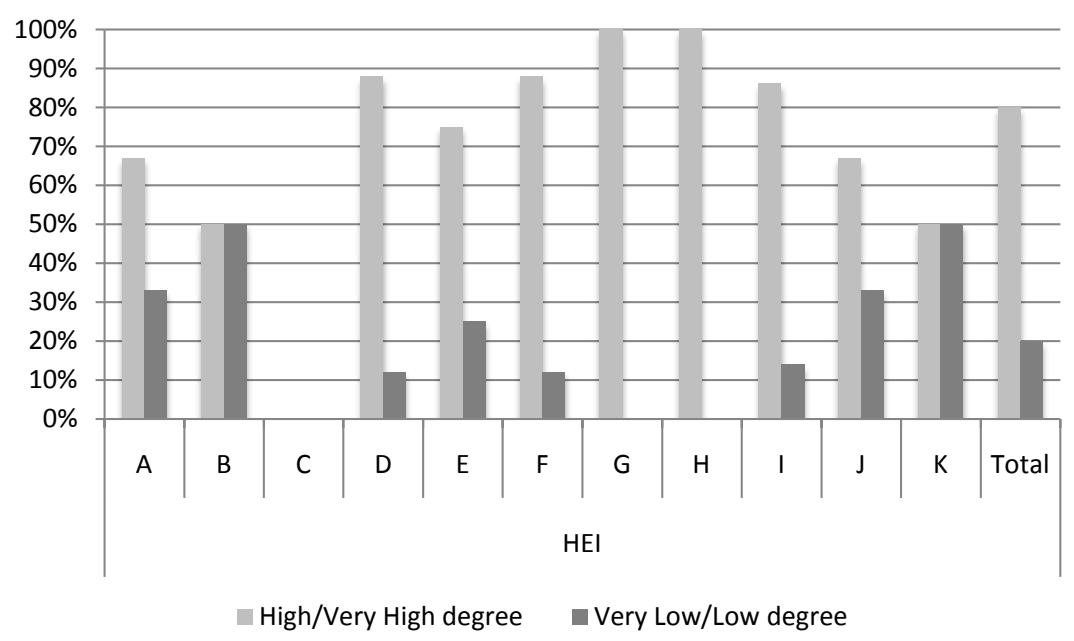

Figure 3. Nursing students self-reported assessment to what extent their International Study Experience (ISE) had contributed to their competence development $(n=55)$ (The HEI labeled as C did not have any students participating in ISE).

safe care. The reasons why the nursing students with ISE rated their competence higher on the three competence areas cannot be explained by this study. However, it can assumed that being exposed to health-care systems in low-income countries where patients' rights are not always obvious [24] may initiate a critical thinking among the nursing students that leads to a higher awareness of importance of patients' rights. Likewise, entering into a foreign and different caring environment may lead to development of a better managing of new challenging situations and the development of the students' competence in managing these situations and also in developing their leadership skills. In addition, a majority of the nursing students had performed their ISE in low-income countries where there is a shortage of health-care professionals and where informal care performed by relatives is common. This is likely to enhance the training of teaching and supervision to relatives and untrained staff.

Several key documents stress the importance of internationalization in higher education, in order to promote understanding of other countries and international conditions, and encourage student mobility [19] [25]. However, a previous national study from 2008 including 24 out of 25 general nursing program in Sweden found that only $41 \%$ of students in their final semester perceived that their education had contributed to their understanding of people with other cultural or ethnic backgrounds [26]. A likely reason for this could be that relatively few students had participated in ISE programs as part of their nursing studies. The current study showed that in spite of the stressed importance of internationalization during basic nursing education, five years later on an average only $11 \%$ of the students at the 11 HEIs (though not equally distributed per HEI) had carried out part of their education abroad which is regrettable as the nursing students expressed how valuable the ISE had been for their competence development. Factors identified as impacting on students participation in ISE were living situation, having children, commitments beside nursing studies, lack of finance, perceiving that the HEI had an international focus, previous studies/work abroad and other reasons such as not wanting to be away from home for a long time. To approach the problem of hindering factors so that a greater proportion of students can benefit from internationalization is essential with a significant leadership, further development of teachers, and innovative development of internationalization within education, for example utilizing information technology [27]. There is a lack of data regarding the long-term benefits and effects of ISE [28] and by asking nurses who have been working for a period of time to explain in what way their ISE has been useful in their professional work would give new and important knowledge.

The utilization of government-sponsored scholarships among the group of students with ISE was low. This might reflect negative or reserved attitudes towards internationalization among the decision-makers and teachers at the HEIs, as the scholarships are applied for and obtained based on applications from teachers at the HEIs. Previous research has shown that nursing teachers have had difficulties in integrating internationalization in their teaching [29], and that there is a need to provide assistance in the transition from being a local to becoming a global teacher [7] [8]. Attracting more nursing students to study abroad depends partly on proficient HEIs. More research is warranted to assess the competence and attitudes of decision-makers and teachers in areas re- 
garding internationalization of educational programs.

It is possible to enhance students to participate in ISE as shown by the results for the HEI labeled F. At this HEI almost $30 \%$ of the students had performed part of their education abroad. The HEI had at the time of the data collection undergone an intense internationalization program. This included international preparatory courses given to both students and teachers, which resulted in an increase in government-funded grants for ISE activities. However, to benefit from the ISE experience both individually and for the HEI it is crucial with a structured preparatory course and follow-ups once the student returns from the ISE in the form of clinical placement and/or theoretical courses. The study demonstrated a difference regarding how satisfied the nursing students were with their ISE depending on which HEI they had studied at. Potential factors influencing students' experience of satisfaction with their ISE could be related to the kind of preparation received prior to studying abroad, the characteristics and quality of the host HEI, and post-ISE follow-up among nursing students. Based on our international experience we clearly see the value of well organized and structured program activities to support internationalization. This will enable students to make the most out of their international exposure and lead to good quality of care for patients including cultural appropriate care.

\section{Conclusion}

International Study Experience (ISE) during the basic nursing education has a positive impact on newly graduated nurses' self-reported competence, especially legislation in nursing and safety planning, leadership and developing of nursing and education and supervision of staff and students. Measures should be taken to actively offer as many nursing students as possible the opportunity to do part of their clinical and/or theoretical education in other countries.

\section{Acknowledgements}

We are grateful to the nursing students for their participation in this study, Hilary Hocking, Östersund, Sweden for language revision, and JariAppelgren, Karlstad University, Sweden for statistical advice.

\section{References}

[1] International Counsel of Nurses (2012) Reforming Primary Health Care: A Nursing Perspective. International Counsel of Nurses, Geneva.

[2] Bentley, R. and Ellison, K.J. (2007) Increasing Cultural Competence in Nursing through International Service-Learning Experience. Nurse Educator, 32, 207-211. http://dx.doi.org/10.1097/01.NNE.0000289385.14007.b4

[3] Koskinen, L. and Jokinen, P. (2007) Multicultural Healthcare: A Transatlantic Project. Nurse Educator, 32, 89-93. http://dx.doi.org/10.1097/01.NNE.0000264330.63662.cd

[4] Davidhizar, R. and Shearer, R. (2005) When Your Nursing Student Is Culturally Diverse. The Health Care Manager, 24, 38-42. http://dx.doi.org/10.1097/00126450-200510000-00009

[5] Freda, M. (1998) International Nursing and World Health: Essential Knowledge for the 21st Century Nurse. MCN: The American Journal of Maternal/Child Nursing, 23, 329-332. http://dx.doi.org/10.1097/00005721-199811000-00010

[6] Maas-Garcia, L. (2011) Benchmarking One's Health Care System: Professional Development through an International Experience. Nurse Education in Practice, 11, 293-297. http://dx.doi.org/10.1016/j.nepr.2011.01.005

[7] Lepp, M., Halabi, J. and Määttä, S. (2011) Jordanian Nursing Faculty Experiences of Participation in International Exchange Programmes with Sweden. Diversity in Health and Care, 8, 181-188.

[8] Määttä, S. and Lepp, M. (2010) Swedish Nursing Faculty Experiences of Participation in International Exchange Programmes. Diversity in Health and Care, 7, 35-42.

[9] Carlton, K.H., Ryan, M., Ali, N.S. and Kelsey, B. (2007) Integration of Global Health Concepts in Nursing Curricula: A National Study. Nursing Education Perspective, 28, 124-129.

[10] McAuliffe, M.S. and Cohen, M.Z. (2005) International Nursing Research and Educational Exchanges: A Review of the Literature. Nursing Outlook, 53, 21-25. http://dx.doi.org/10.1016/j.outlook.2004.10.004

[11] Bosworth, T.L., Haloburdo, E., Hetrick, C., Patchett, K., Thompson, M.A. and Welsch, M. (2006) International Partnership to Promote Quality Care: Faculty Groundwork, Student Projects and Outcomes. The Journal of Continuing Education in Nursing, 37, 32-38.

[12] Green, B.F., Johansson, I., Rosser, M., Tengnah, C. and Segrott, J. (2008) Studying Abroad: A Multiple Case Study of 
Nursing Students' International Experiences. Nurse Education Today, 28, 981-992. http://dx.doi.org/10.1016/j.nedt.2008.06.003

[13] Inglis, A., Rolls, C. and Kristy, S. (2000) The Impact on Attitudes towards Cultural Difference of Participation in a Health Focused Study Abroad Program. Contemporary Nurse, 9, 246-255. http://dx.doi.org/10.5172/conu.2000.9.3-4.246

[14] Lee, R.L., Pang, S.M., Wong, T.K. and Chan, M.F. (2007) Evaluation of an Innovative Nursing Exchange Programme: Health Counselling Skills and Cultural Awareness. Nurse Education Today, 27, 868-877. http://dx.doi.org/10.1016/j.nedt.2006.12.002

[15] Leinonen, S.J. (2006) International Nursing Exchange Programs. Journal of Continuing Education Nursing, 37, 16-20.

[16] Wros, P. and Archer, S. (2010) Comparing Learning Outcomes of International and Local Community Partnerships for Undergraduate Nursing Students. Journal of Community Health Nursing, 27, 216-255. http://dx.doi.org/10.1080/07370016.2010.515461

[17] Kokko, R. (2011) Future Nurses' Cultural Competencies: What Are Their Learning Experiences during Exchange and Studies Abroad? A Systematic Literature Review. Journal of Nursing Management, 19, 673-682. http://dx.doi.org/10.1111/j.1365-2834.2011.01221.x

[18] Kulbok, P.A., Mitchell, E.M., Glick, D.F. and Greiner, D. (2012) International Experiences in Nursing Education: A Review of Literature. International Journal of Nursing Education Scholarship, 9, 1-21. http://dx.doi.org/10.1515/1548-923X.2365

[19] SFS (1992) Higher Education Act. Swedish Statue Book, Stockholm, 1434.

[20] Nilsson, J., Johansson, E., Egmar, A.C., Florin, J., Leksell, J., Lepp, M., Lindholm, C., Nordström, G., Theander, K., Wilde-Larsson, B., Carlsson, M. and Gardulf, A. (2014) Development and Validation of a New Tool Measuring Nurses Self-Reported Professional Competence-The Nurse Professional Competence (NPC) Scale. Nurse Education Today, 34, 574-580. http://dx.doi.org/10.1016/j.nedt.2013.07.016

[21] The National Board of Health and Welfare (2005) Competence Requirements for Registered Nurses. Stockholm.

[22] Ministry of Education and Research (2003) The Swedish Act on the Ethical Review of Research Involving Humans in Swedish. Stockholm. http://www.riksdagen.se/sv/Dokument-Lagar/Lagar/Svenskforfattningssamling/Lag-2003460-om-etikprovning sfs-200 $\underline{3-460 /}$

[23] Theisen, J.L. and Sandau, K.E. (2013) Competency of New Graduate Nurses: A Review of Their Weaknesses and Strategies for Success. Journal of Continuing Education in Nursing, 44, 406-414. http://dx.doi.org/10.3928/00220124-20130617-38

[24] Gribble, N., Dender, A., Lawrence, E., Manning, K. and Falkmer, T. (2014) International WIL Placements: Their Influence on Student Professional Development, Personal Growth and Cultural Competence. Asia-Pacific Journal of Cooperative Education, 15, 107-117.

[25] The European Higher Education Area (1999) The Bologna Declaration of 19 June 1999. Joint Declaration of the European Ministers of Education. http://www.ehea.info/Uploads/about/BOLOGNA DECLARATION1.pdf

[26] Håård, U.S., Öhlén, J. and Gustavsson, P.J. (2008) Generic and Professional Outcomes of a General Nursing Education Program-A National Study of Higher Education. International Journal of Nursing Education Scholarship, 5, 1-18. http://dx.doi.org/10.2202/1548-923X.1611

[27] Lepp, M., Zorn, C.R., Duffy, P.R. and Dickson, R.J. (2005) Swedish and American Nursing Students Use Journaling for Reflection: An International Student-Centered Learning Experience. International Journal for Human Caring, 9 , 52-58.

[28] Kirkham, S., Van Hofwegen, L. and Pankratz, D. (2009) Keeping the Vision: Sustaining Social Consciousness with Nursing Students Following International Learning Experiences. International Journal of Nursing Education Scholarship, 6.

[29] Svensson, L. and Wihlborg, M. (2007) Internationalization in the Swedish Nurse Education from the Perspective of Teachers Involved: An Interview Study. Journal of Higher Education, 53, 279-305. http://dx.doi.org/10.1007/s10734-005-8157-3 
Scientific Research Publishing (SCIRP) is one of the largest Open Access journal publishers. It is currently publishing more than 200 open access, online, peer-reviewed journals covering a wide range of academic disciplines. SCIRP serves the worldwide academic communities and contributes to the progress and application of science with its publication.

Other selected journals from SCIRP are listed as below. Submit your manuscript to us via either submit@scirp.org or Online Submission Portal.
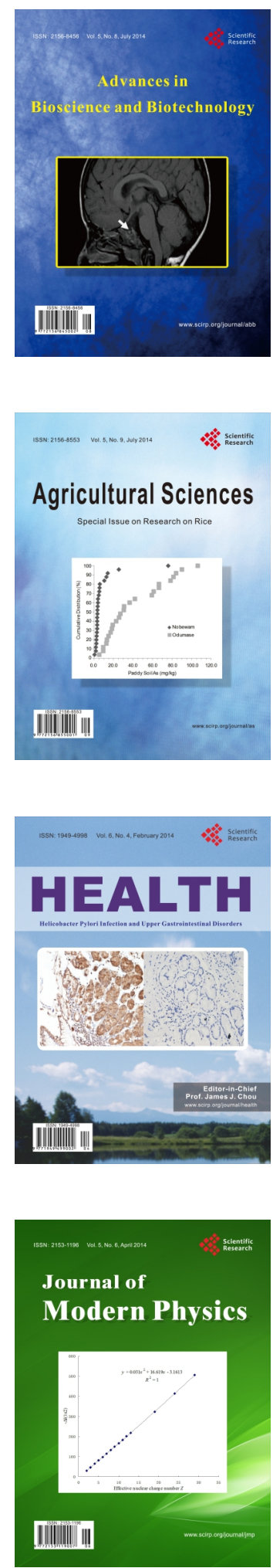
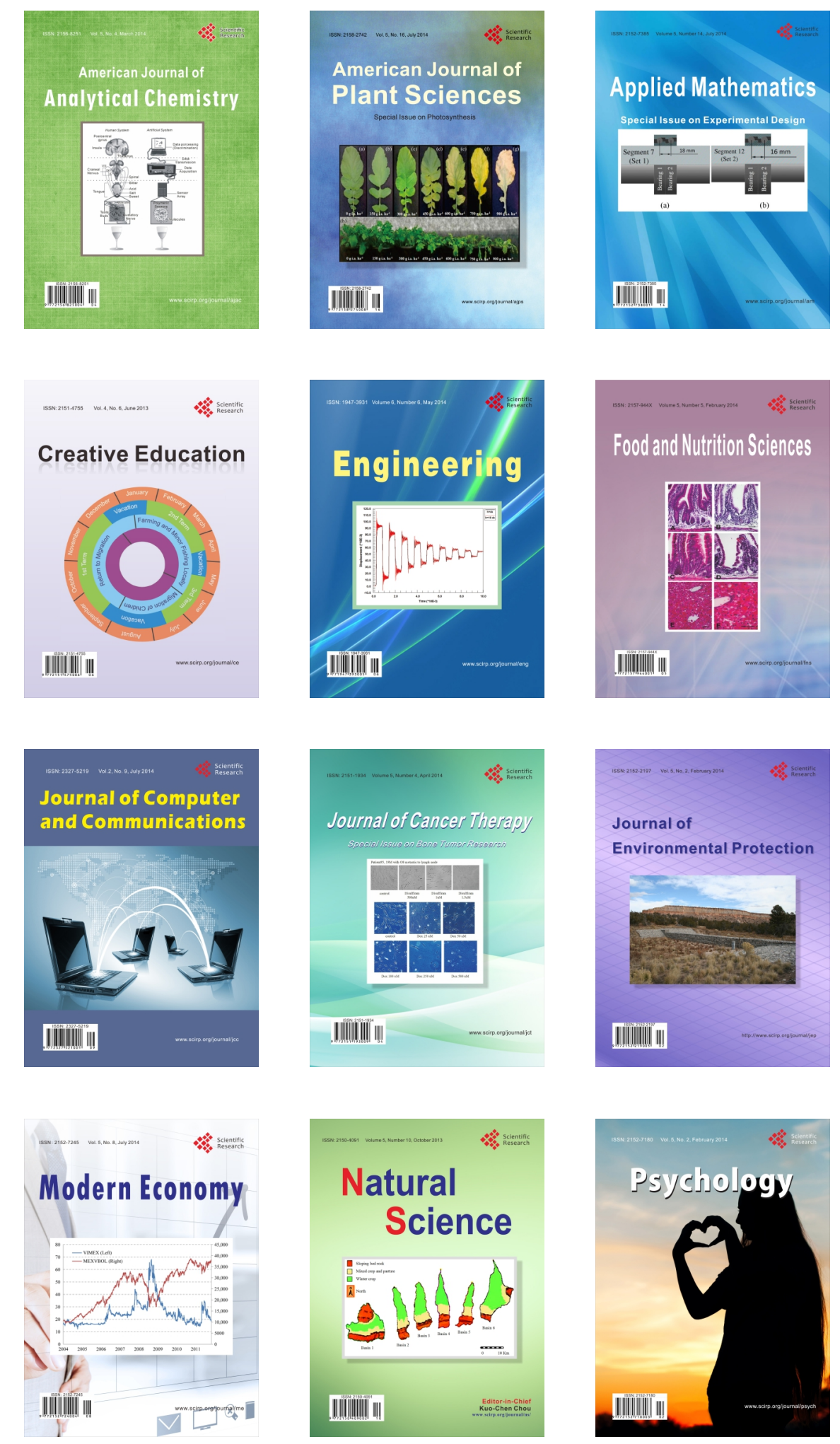